بررسى تأثير مواد افزودنى بر كارايى علف كش نيكوسولفورون در كنترل تاجخروس ريشه قرمز (Amaranthus retroflexus)

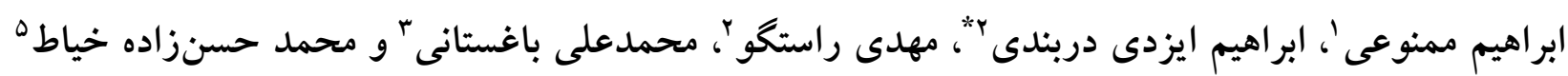

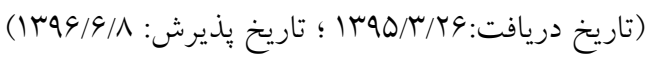

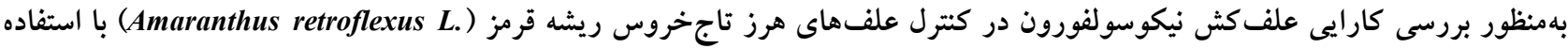

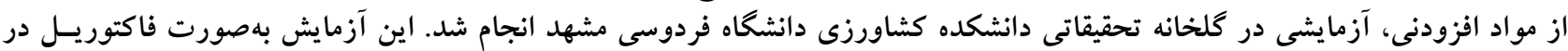

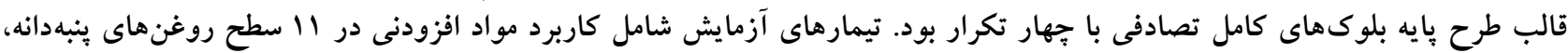

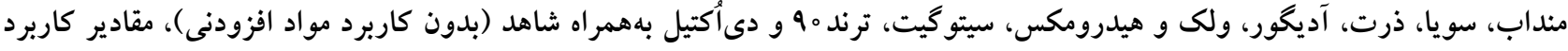

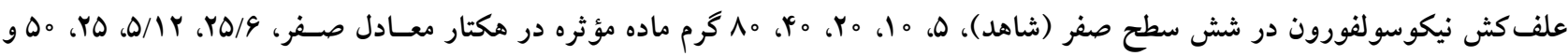

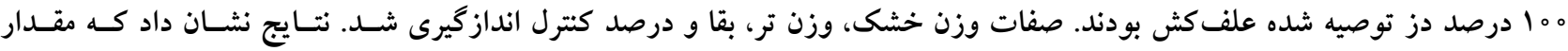

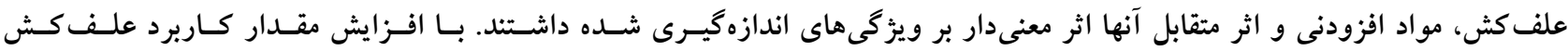

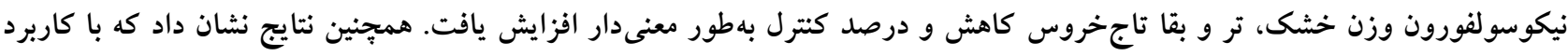

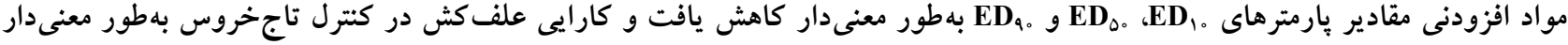

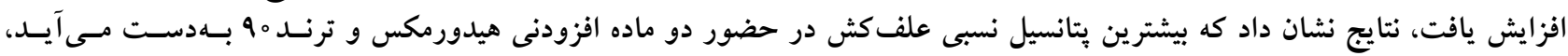

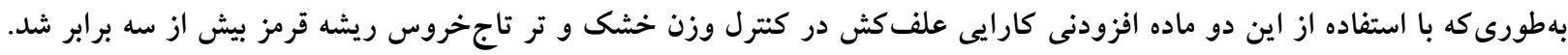

وازههاى كليدى: ترند، هيدرومكس، مDD

ا. دانش آموخته دكترى گروه زراعت، دانشكده كشاورزى، دانشخاه فردوسى مشهد و مربى بخش تحقيقات گياهيزشكى، مركز تحقيقات و آموزش

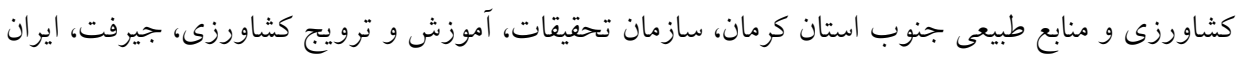

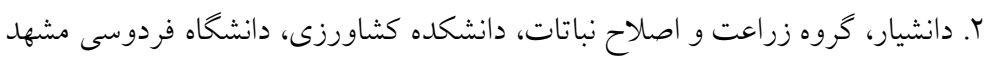

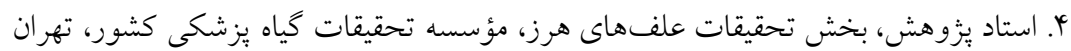

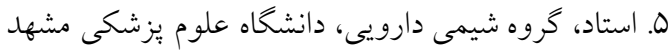

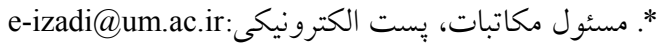


به كار مىرود، يا مى توانند همر اه با علـفكـش در زمـان مصـرف

بهصورت مخلوط در تانك سمياش مورد استفاده قرار بخيـرد (ه).

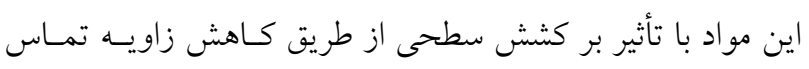

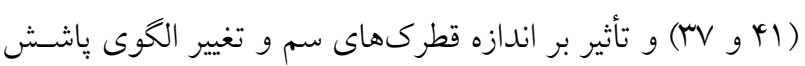

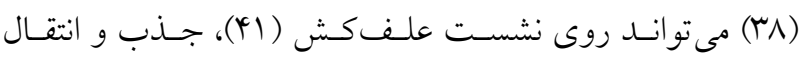
علف كش (r^) مؤثر باشند. هم:جنين مواد افزودنى با ايجاد تـأخير

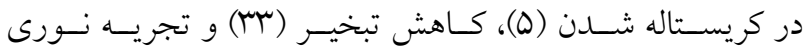

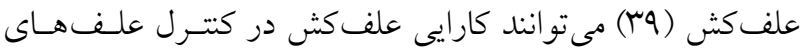
هرز را افزايش دهند (9، 1). ايزدى و همكاران (91) عقيـده دارنـــ

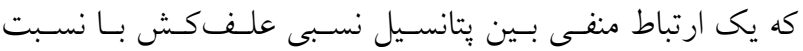
اسيدهاى جرب غيراشباع به اشباع در مـواد افزودنسى وجـود دارد (1) بهطورى كه با افزايش تعداد باند و طول زنجيره هيدروكربنى

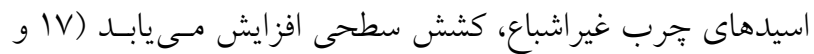

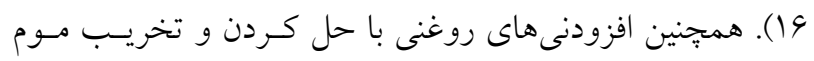
كوتيكول و ايجاد ترك بر روى اين لايه مىتوانند به نفوذ و انتقـال

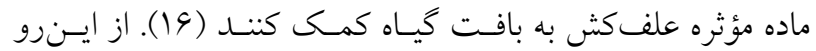
امروزه، استفاده از مويانهاى روغنى بهعنوان عوامل نفـوذ دهنــهـ

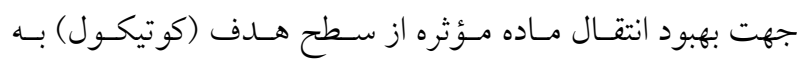

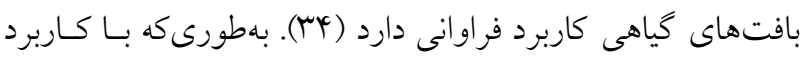

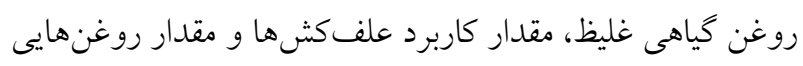
كه بهعنوان حامل استفاده مىشوند را كاهش دادهاند (با). بهعنـوان

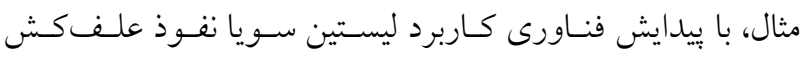
افزايش يافته است. عقيده بر اين است كـه ايـن مـاده بــا تشـكيل

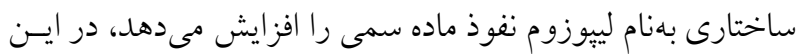

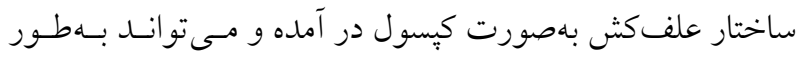
آزادانه از بين كوتيكول كياه عبور كنــ (MY). مطالعـات نشـان داده است كه سـرعت تجزيـهـ و متابوليسـمم افزودنسىهـاى گيـاهى در مقايسه با مو اد معلنى بيشتر اسـت (V) بنـابر اين بـا كـاربرد مـواد افزودنى گياهى مىتوان مقدار خسارتى كه به محسيط زيست وارد كند تا حدى كاهش داد (IV). در همين راستا، ايزدى و همكـاران كزارش كردند كه با كـاربرد مـواد افزودنسى روغـن گيـاهى (IV)

كرجـى (Ricinus communis L.)، زيتـون (Olea europaea L)،
يكى از مهمترين عوامل محدود كننده توليـد در محصـولات زراعىى،

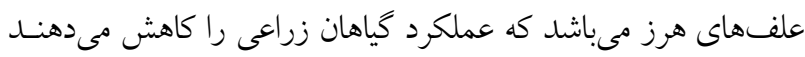

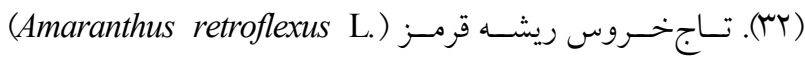
بهنوان يكى از مهمترين علف هرز غالب در دنيـا (؟)) و كشـورمان

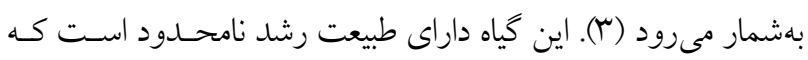

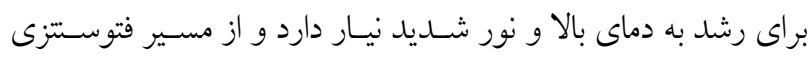

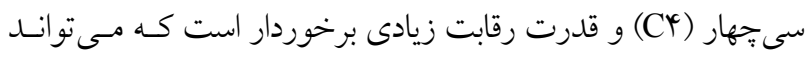

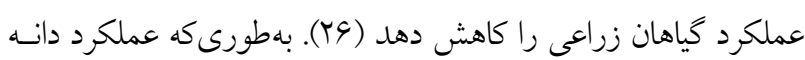

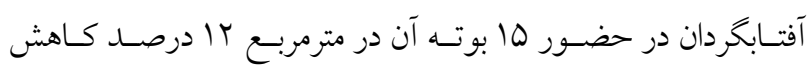

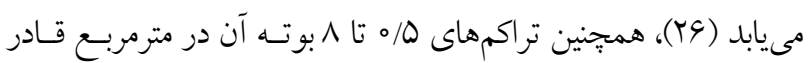

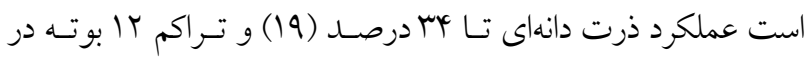

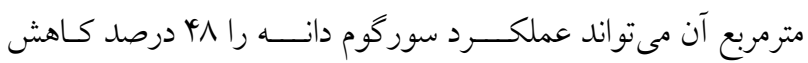

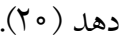

علف كش نيكوسولفورون از خروه سولفونيل اوره است، كـهـ

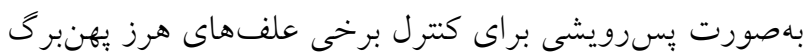

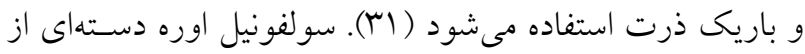

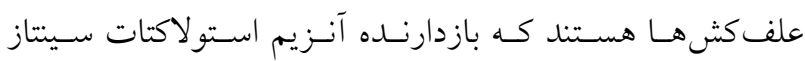
است و مانع ساخت اسيدهاى آمينه زنجيرهاى مىباشــنـ

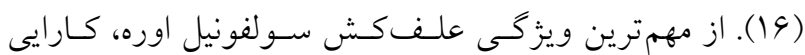
مطلوب آن در كتترل علف هاى هرز، مقدار مصرف كـمـ آنهـا در

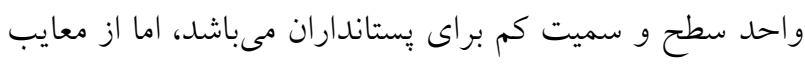

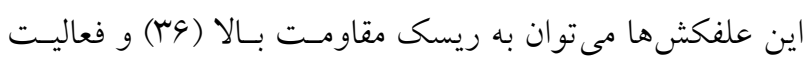

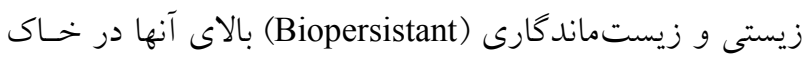

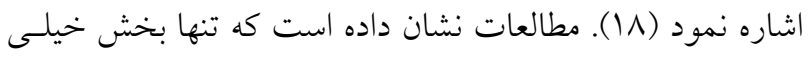

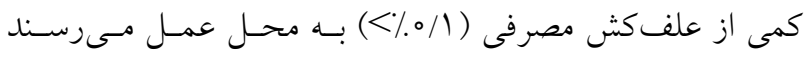

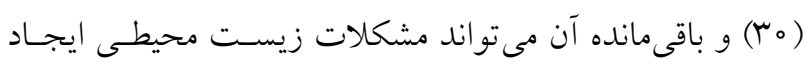

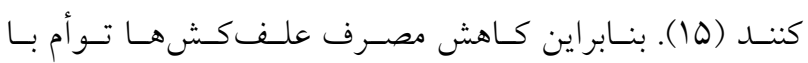

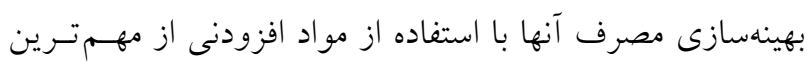
راهكارهاى است كه مى توان خسارت علف كشها را به حسداقل

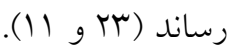
مواد افزودنى يا در زمـان توليــ در فرمولاسـيون علـفكـش 
آزمايش بلهورت فاكتوريل در قالب طرح بايـه بلـوكهـاى

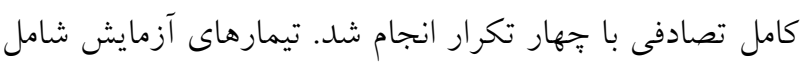

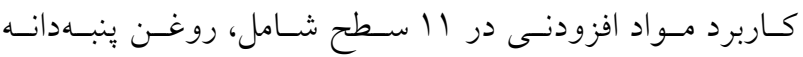
(Gossypium hirsutum L) ، منــاب (Eruca sativa L)، سويا

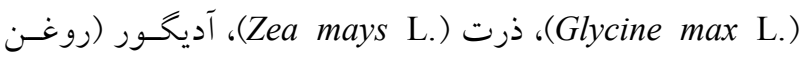

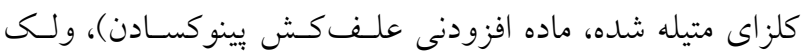

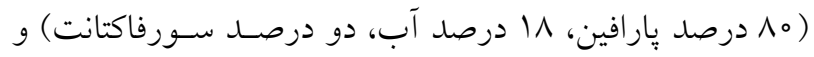
هيدرومكس (9 درصد عصاره يوكا، دو درصد اسيد هيوميك،

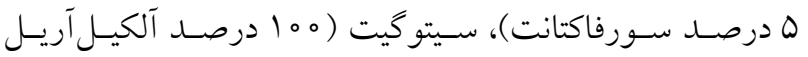
يلى گليكول اتوكسيلات)، ترنده9 (ايزودسيل الكل اتوكسـيلات)

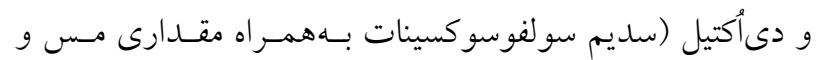
موليبـدن) بـههمـراه شـاهد بــدون كـاربرد مـواد افزودنسى بــود. روغنهاى كياهى بهصورت خالص از شركت سه گل نيشابور و

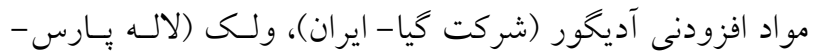

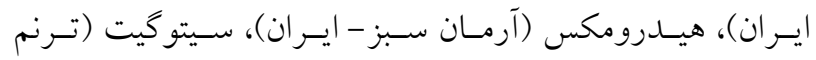

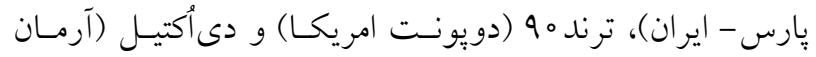

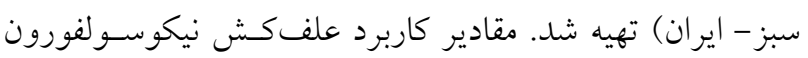

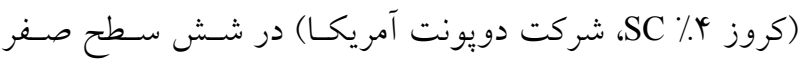

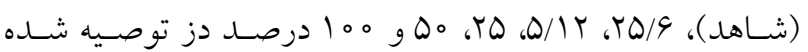
علف كش (مقدار توصيه شده دو ليتر در هكتـار)، معـادل صـفر

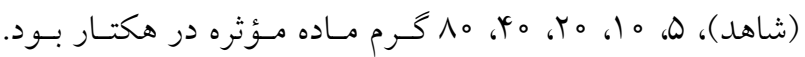

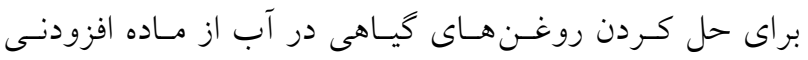

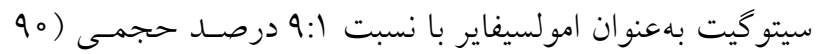

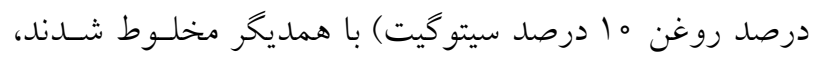

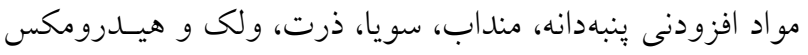

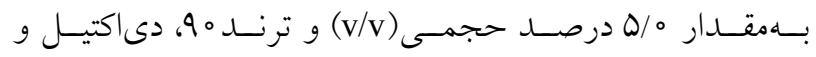
سيتو كيت بهمقدار / / درصد حجمى(v/v) استفاده شد. بذرها در داخل كلدانهاى بِلاستيكى به قطر ها سانتىمتر و

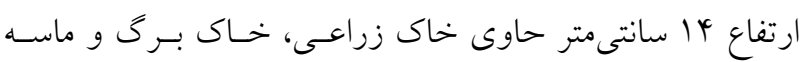

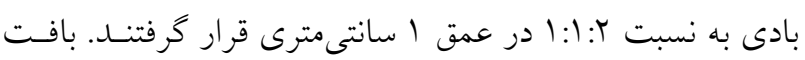

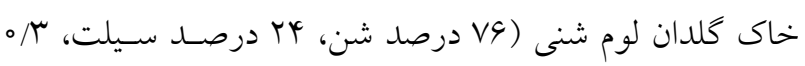

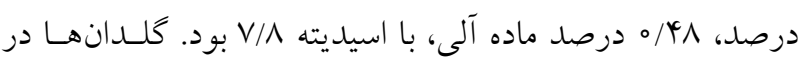

سـويا (Glycine max L)، ينبـه (Gossypium hirsutum L)، كنجـــ

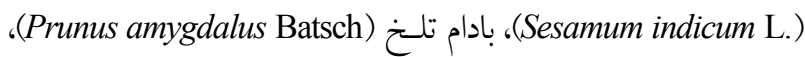
بادام شيرين (Brassica napus L علـفــشهــاى ايماز امتـابنزمتيـل، ستوكسيدم و سولفوسـولفورون مىتوان كـارايى كتـــل يـولاف وحشىى (Avena fatua L. بـهـور

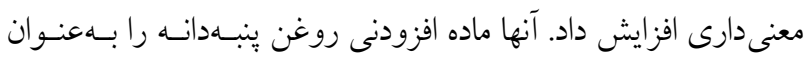
مؤثرترين ماده افزودنى در بهبود كاريى علف كش هاى معرفى كردنـــ.

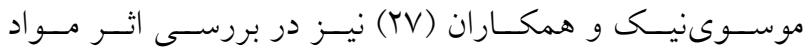

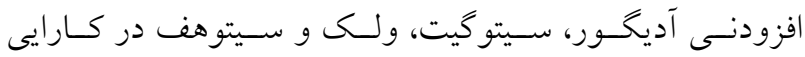

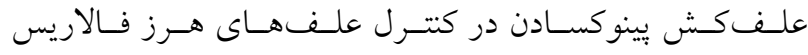
(Phalaris minor Retz.) (Avena fatua L.) و ولاف وحشى )

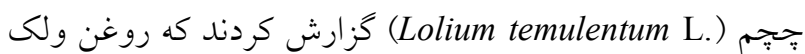
بيشترين تأثير در افزايش كارايى علف كش ينيوكسادن در كتــرل

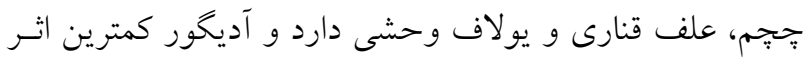
در كنترل يولاف وحشى داشت. از سوى ديخر، اثر ماده افزودنى سيتوهف در افزايش كـارايى علـفكـش يينوكسـادن در كتــــل

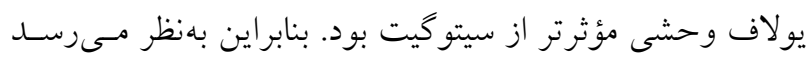

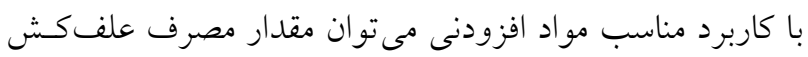
را بدون ايجاد نقصانى در كاريى آن كـاهش داد كـه از ديـدكاه

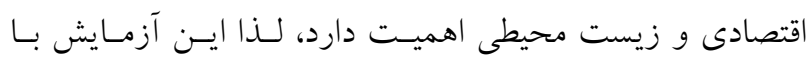
هدف بهينهسازى مصرف علف كث نيكوسو لفوورن با استفاده از مو اد افزودنى در كنترل تاجخروس ريشه قرمز انجام شد.

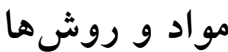

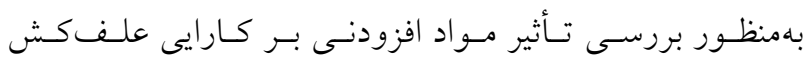

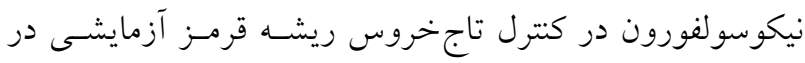

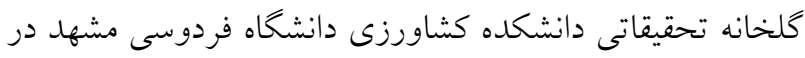

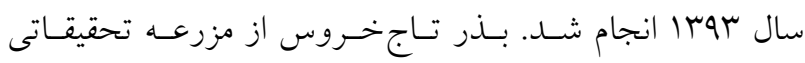

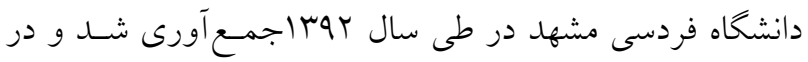

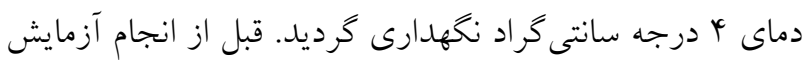
ابتدا قوه ناميه بذر تست شد و خواب بذور با يـك دقيقـه قـرار دادن در اسيد سولفوريك غليظ (19 درصد) شكسته شد. 
مقايسه ميانكين صفات وزن خشـى، تـر و درصــ كتـــرل و بقـا

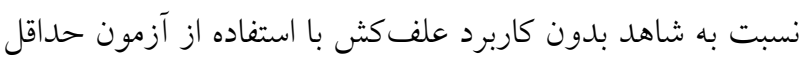
تفاوت معنى دار (LSD) در سطح احتمال ينج درصد بـان نــرمافـزار

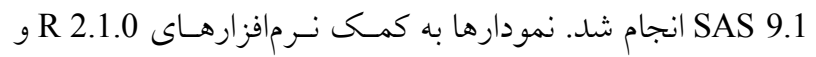
Sigma Plot 12.5

$$
\mathrm{R}=\frac{\mathrm{ED}_{\downarrow_{\bullet}}}{\mathrm{ED}_{\diamond_{\circ}+\mathrm{adj}}}
$$

\section{نتايج و بحث}

نتايج تجزيـه واريـانس نشـان داد كـهـ مقــار علـفــش و مـاده افزودنى اثر معنى دار بر وزن خشك، تر، بقا و درصد كنتـرل دارد. همجنين كنش متقابل مقدار علف كش و ماده افزودنى بهجـز وزن

خشك و درصد بقا در ساير صفات معنىدار بود (جدول ().

\section{وزن خشك و تر علف هرز تاجخروس}

نتايج واكنش تاجخروس ريشه قرمز بهمقدار كاربردى علـفكـش

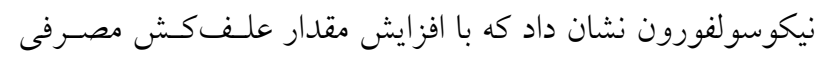
وزن خشك، تر و درصد بقا اين علف هرز كاهش و درصد كتترل

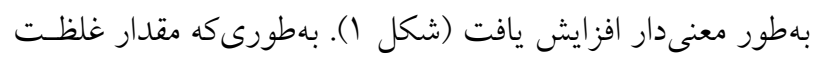

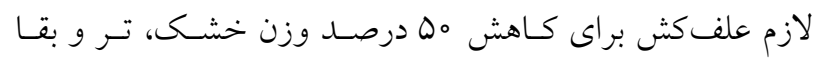

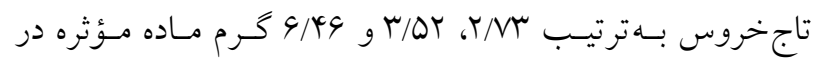

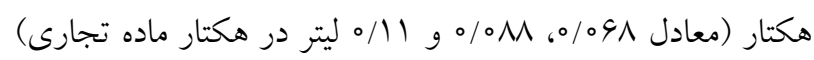

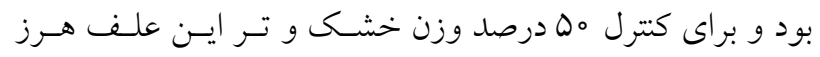

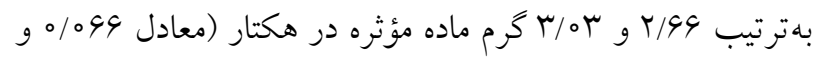

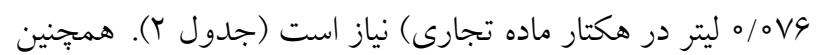

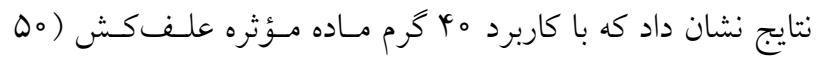

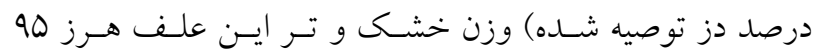

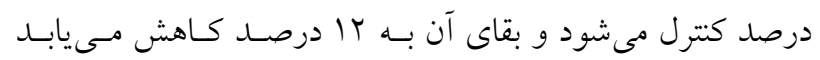

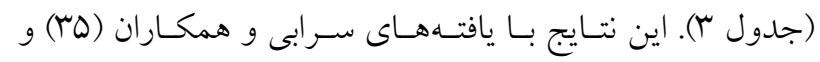

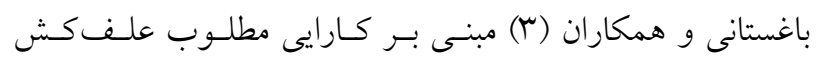
نيكوسو لفورون در كترل تاجخروس ريشـه قرمـز مطابقـت دارد.

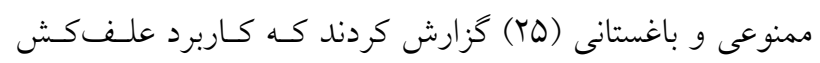

دماى ها دماى درجه سانتى گـراد بـا تنـاوب نـورى 19 سـاعت

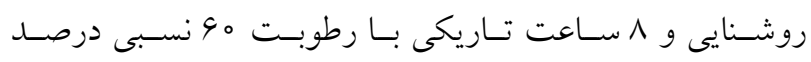

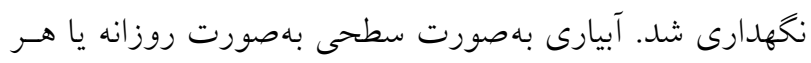

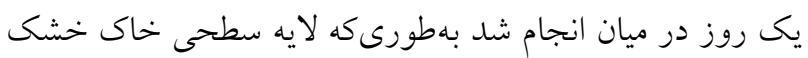

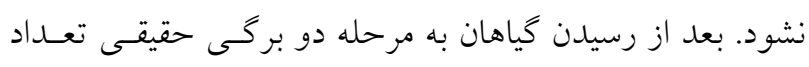

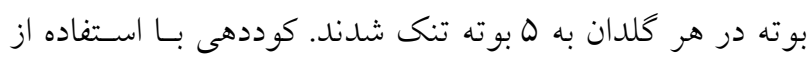

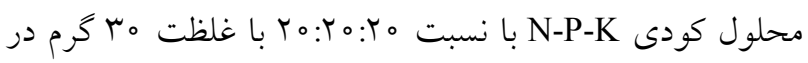

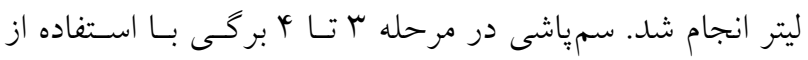

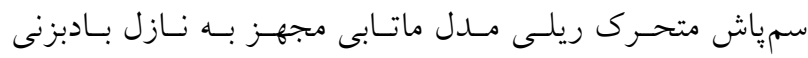

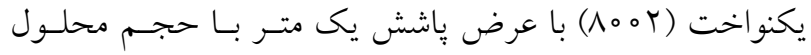

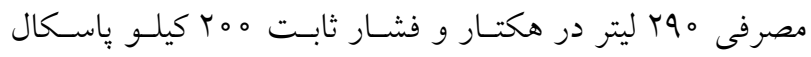
انجام شد. جهار هفته بعد از سمياشى درصد بقا، از طريق نسبت

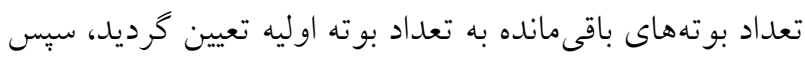
بوتههاى هر كلدان برداشت و وزن تر و خشك (بعد از كذاشتن

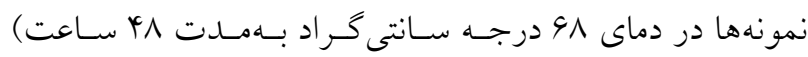

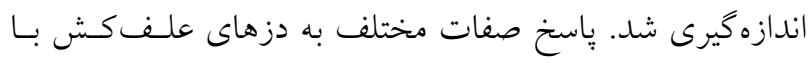

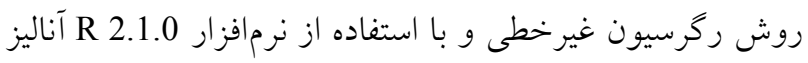

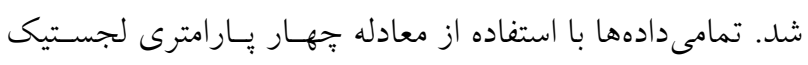

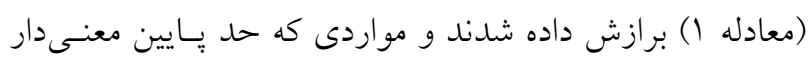

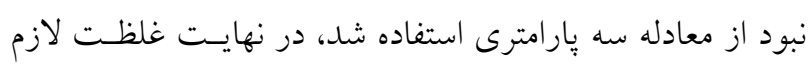

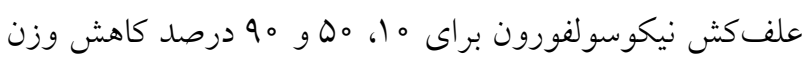
تر و خشى تاجخروس محاسبه گرديد.

$\mathrm{Y}=\mathrm{C}+\frac{\mathrm{D}-\mathrm{C}}{1+\exp ^{\left(\mathrm{b}\left(\log (\mathrm{x})-\log \left(\mathrm{ED}_{\diamond^{\circ}}\right)\right)\right)}}$

در معادله يك Y وزن خشك علف هرز، غلظت علـفكـش (X)، يارامتر D و Cبهترتيب حد بالاو و پايين، b طيب منحنى در نقطـه

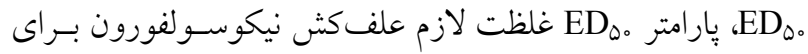

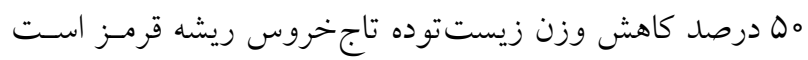

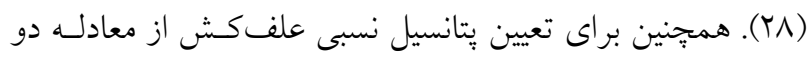

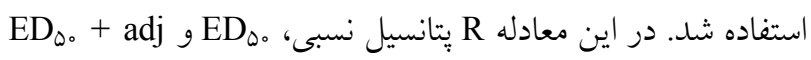

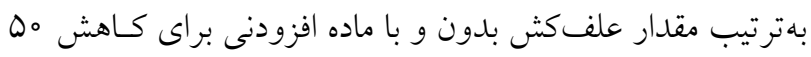

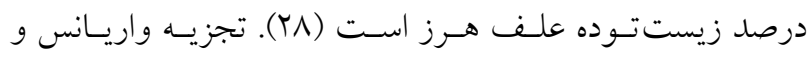


جدول ا. نتايج تجزيه واريانس مقادير مصرف علف كش و ماده افزودنى تاجخروس ريشه قرمز

\begin{tabular}{|c|c|c|c|c|c|c|}
\hline \multicolumn{5}{|c|}{ ميانخين مربعات } & \multirow[b]{2}{*}{$\mathrm{df}$} & \multirow[b]{2}{*}{ منابع تغيير } \\
\hline درصد بقا & درصد كترل & وزن تر & وزند كنترل & وزن خشك & & \\
\hline$V I^{* *}$ & $|\Lambda|^{* *}$ & $0 / 9 Y^{* *}$ & $r V e^{* * *}$ & $\circ / 19^{* *}$ & r & 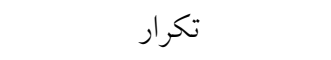 \\
\hline Dr\&99** & $G \circ Y \wedge r^{* *}$ & $1 \circ \mu^{* * *}$ & $q \circ V \circ q^{* *}$ & $r Q^{* *}$ & $\Delta$ & مقدار كاربرد علف كش (H) \\
\hline$\wedge \circ 9^{* *}$ & $\psi V^{* *}$ & $1 / \wedge 4^{* *}$ & $\varphi \circ l^{* *}$ & $\circ / 1 Q^{* *}$ & 10 & ماده افزودنى (A) \\
\hline 114 & $104^{* *}$ & $\circ / \Upsilon \wedge^{* *}$ & $11 V^{* *}$ & $\circ / q_{9}$ & Q० & $\mathrm{H} \times \mathrm{A}$ \\
\hline IrT & r & $0 / 14$ & $\Delta S$ & $\circ / \circ$ & 190 & خطا \\
\hline$\mu_{\circ}$ & m & M & 11 & $\mu_{0}$ & & ضريب تغييرات (CV) \\
\hline
\end{tabular}
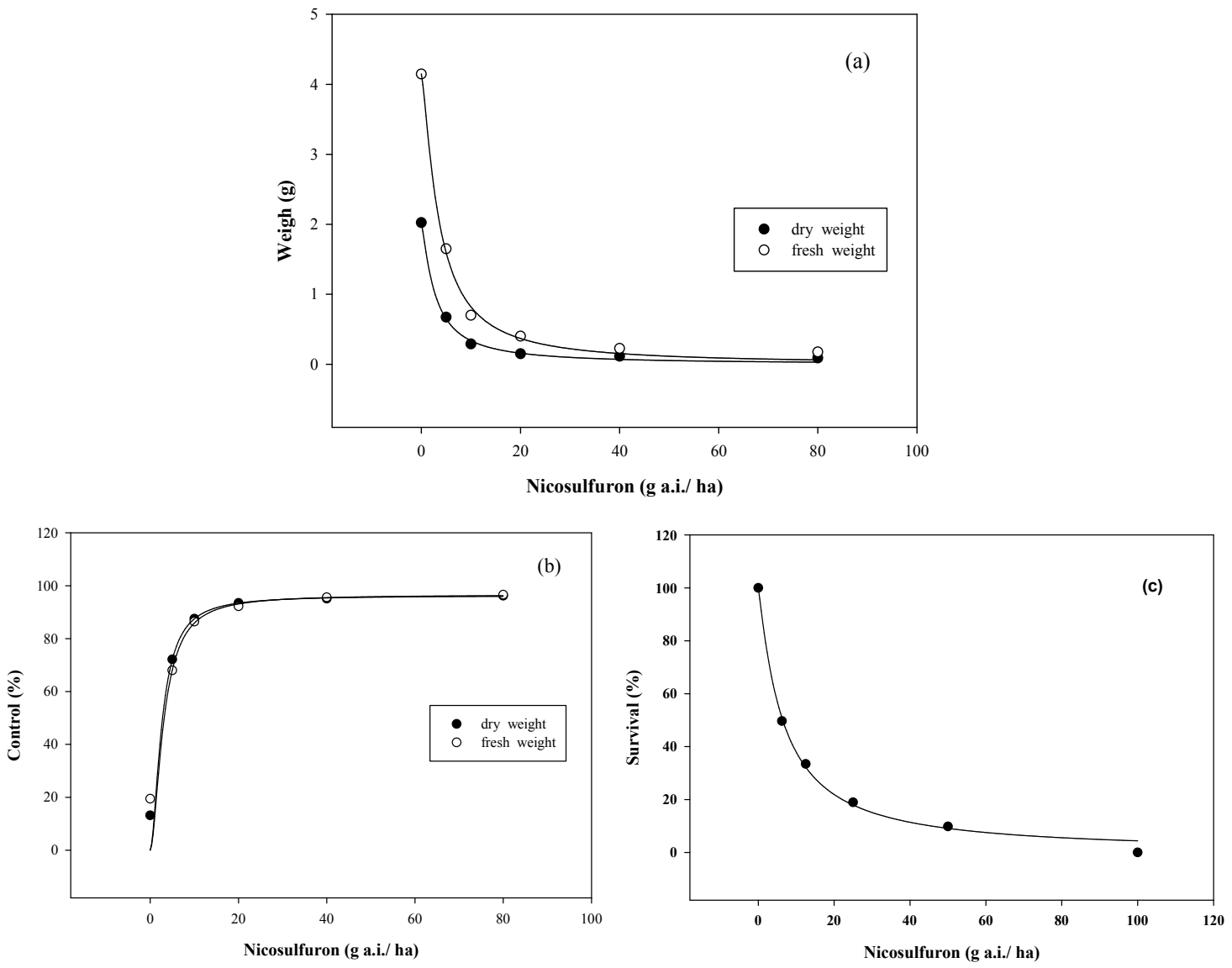

شكل 1. منحنى دز - ياسخ تاجخروس ريشه قرمز به مقادير مختلف علف كث نيكوسولفورون در سطوح مواد افزودنى مختلف 
جدول r. نتايج تجزيه و تحليل رگرسيونى غير خطى واكنش تاجخروس ريشه قرمز به مقادير مختلف علفكش نيكوسولفورون

\begin{tabular}{|c|c|c|c|c|c|c|}
\hline RMSE & $\mathrm{R}^{2}$ & $\mathrm{P}$ & $\mathrm{ED}_{\diamond}$ & شيب (b) & حد بالا (d) & صفات \\
\hline ०/०० & $\circ / 99$ & $<0 / 0001$ & T/NT $(9 / \circ 9)$ & $1 / T Y(\varphi / O Y)$ & $r / \circ r(\circ / \circ D)$ & وزن خشك \\
\hline$\circ / 0 r$ & $0 / 99$ & $<0 / 0001$ & $r / \Delta T(\Lambda / K Y)$ & $1 / N Y(V / Y Y)$ & $4 / 10(0 / 11)$ & و ل وزن تر \\
\hline TY & $0 / 99$ & $0 / 001$ & $0 / 40(1 / 09)$ & $\circ / 9 \wedge(0 / I V)$ & $99 / 09(Y / \Lambda 1)$ & درصد بقا \\
\hline.$/ 11$ & $0 / 99$ & $\circ / \circ \circ \circ \mathrm{V}$ & $r / 99(1 / V 0)$ & $-1 / V Y(1 / 00)$ & $99 / Y Y(9 / 09)$ & درصد كنترل وزن خشك \\
\hline $1 / 19$ &.$/ 94$ & ०००५० & $r / \circ r(r / \circ q)$ & $-I / V D(Y / I Y)$ & $99 / 0 \vee(9 / 19)$ & درصد كنترل وزن تر \\
\hline
\end{tabular}

اعداد داخل بيرانتز نشاندهنده خطاى استاندارد است.

جدول r. مقايسه ميانخين اثر مقادير علفكش نيكوسولفورون بر تاجخروس ريشه قرمز

\begin{tabular}{|c|c|c|c|c|c|}
\hline \multirow{2}{*}{ درصد بقا } & \multicolumn{2}{|c|}{ وزن تر } & \multicolumn{2}{|c|}{ وزن خشك } & \multirow{2}{*}{ 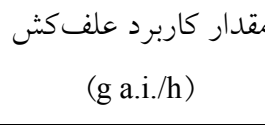 } \\
\hline & (درصد كنترل) & (كرم) & (درصد كتترل) & (كرم) & \\
\hline $100^{a}$ & oe & $r / l^{a}$ & od & $r / \circ r^{\mathrm{a}}$ & 。 \\
\hline$\varphi \wedge^{\mathrm{b}}$ & $4 \wedge^{\mathrm{d}}$ & $1 / 90^{\mathrm{b}}$ & $V l^{c}$ & $0 / 9 \mathrm{~V}^{b}$ & 0 \\
\hline$r q^{c}$ & $\wedge \mathcal{q}^{\mathrm{d}}$ & $\circ / V_{0} \mathrm{c}$ & $\Delta \mathrm{v}^{\mathrm{b}}$ & $0 / T q^{\circ}$ & 10 \\
\hline$r r^{\mathrm{d}}$ & $a r^{b}$ & $o / 4 \circ d$ & $9 r^{\mathrm{a}}$ & $\circ / 10^{d}$ & ro \\
\hline $1 r^{\mathrm{e}}$ & $90^{\mathrm{a}}$ & o/YYe & $90^{a}$ & $\circ / 1^{d}$ & $y_{0}$ \\
\hline of & $99^{\mathrm{a}}$ & $\circ / I V e$ & $99^{\mathrm{a}}$ & $\% / \circ q^{d}$ & $\Lambda_{0}$ \\
\hline$r / 99$ & T/NV & $0 / 19$ & $r / 10$ & $\circ / \circ V$ & $\operatorname{LSD}(\circ / \circ \Delta)$ \\
\hline
\end{tabular}

حروف مشابه در هر ستون بيانخر عدم اختلاف معنى دار در سطح ينج درصد با آزمون حداقل تفاوت معنىدار (LSD) است.

علفكـش نيكوسـولفورون بـر صـفات مـذكور بيشـتر از سـاير

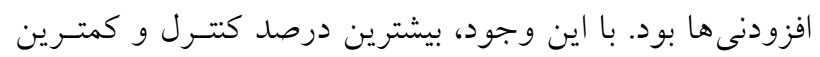

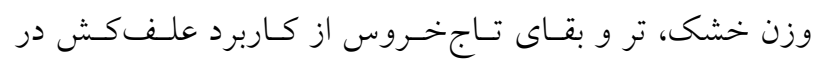

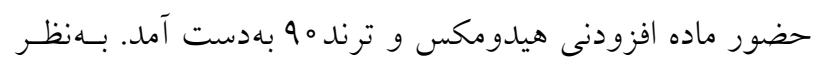

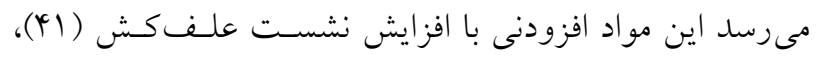

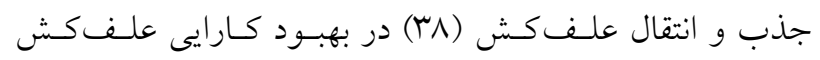

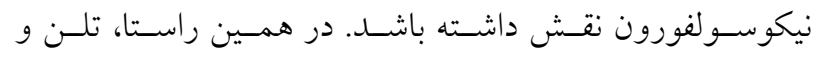

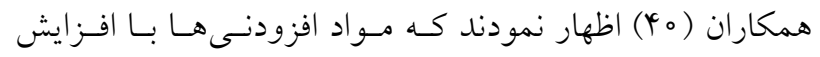

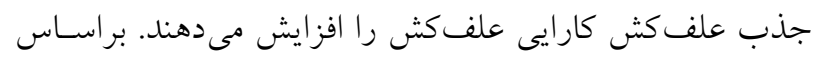

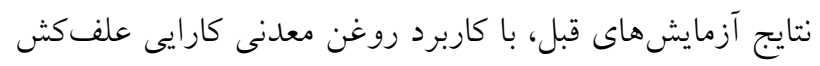

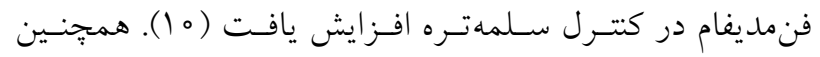

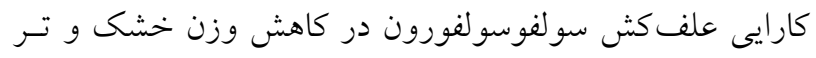

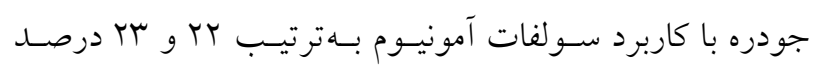

نيكوسولفورون بههمراه بروموكسينيل + امسىيى (برومايسـيدامآ)

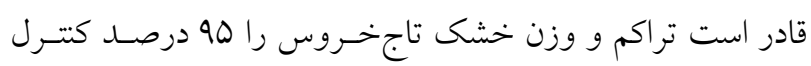

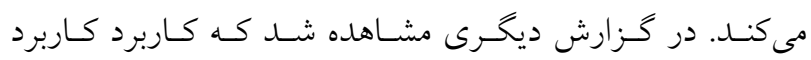

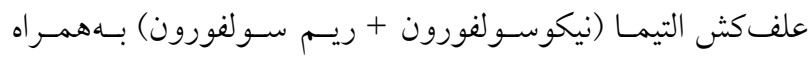

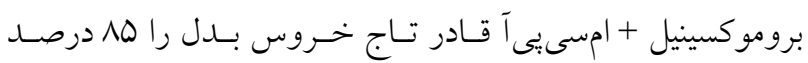

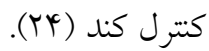
اثر كاربرد مواد افزودنى بهتنهايى (بدون علفكش) بـر وزن خشك و تر تاجخروس ريشه قرمز معنسى دار نبـود (بنـابراين از

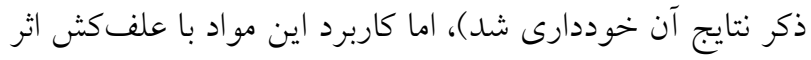
معنىدار بر صفات مذكور داشت، بهطورى كه با كاربرد اين مـواد

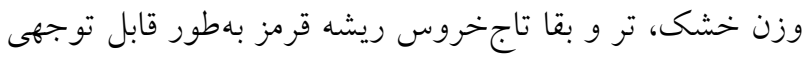

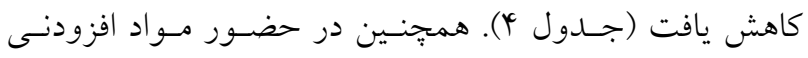

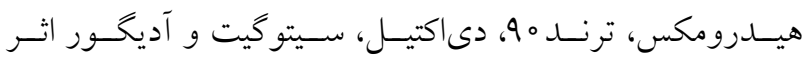


جدول أ. نتايج مقايسه ميانخين اثر ماده افزودنى بر وزن خشك، تر، بقاى تاجخروس و درصد كنترل نسبت به شاهد بدون ماده افزودنى

\begin{tabular}{|c|c|c|c|c|c|}
\hline \multirow{2}{*}{ درصد بقا } & \multicolumn{2}{|c|}{ وزن تر } & \multicolumn{2}{|c|}{ وزن خشك } & \multirow{2}{*}{ تيمار } \\
\hline & درصد كنترل & (كرم) & درصد كنترل & (كرم) & \\
\hline ruc-e & $V^{r b c}$ & $1 / T r^{\mathrm{bc}}$ & $\circ / \Delta \xi^{b-d}$ & $V y^{c a-c}$ & روغن ينبهدانه \\
\hline$y \circ b c$ & $V^{\mu c}$ & $1 /\left.\mu\right|^{b}$ & $\circ / \Delta q b c$ & $V^{\mathrm{bc}}$ & روغن منداب \\
\hline$r \Lambda^{c-d}$ & $V^{\mu c}$ & $1 / T \Delta^{\mathrm{bc}}$ & $\circ / \Delta q b c$ & $V^{\mathrm{bc}}$ & روغن سويا \\
\hline prb & $V Y^{a-c}$ & 1/Trb & $\circ /\left.9\right|^{b}$ & $V Y^{c}$ & روغن ذرت \\
\hline ryde & $V r^{a-c}$ & $1 / \circ \wedge^{c-e}$ & $\circ / \Delta Y^{b-e}$ & $V \varphi^{a-c}$ & آديخور \\
\hline ryde & $V Q^{a-c}$ & $Y / \circ V^{c-e}$ & $\circ / D Y^{c-e}$ & $V \varphi^{a-c}$ & سيتو كيت \\
\hline$\mu \mathrm{e}$ & $V q^{\mathrm{ab}}$ & $0 / 99^{\mathrm{e}}$ & $0 / 4 q$ de & $V^{a b}$ & ترند 9 \\
\hline ruc-e & $V \varphi^{a-c}$ & $1 / 0 Y^{\mathrm{de}}$ & $\circ / 0 \circ \mathrm{c}-\mathrm{e}$ & $V \varphi^{a-c}$ & دى دكتيل \\
\hline yobc & $V y^{c b c}$ & $1 / Y^{c-d}$ & $\circ / \Delta \Delta^{b-d}$ & $v y^{a-c}$ & ولى \\
\hline me & $V^{a}$ &.$/ 9 \mathrm{re}^{\mathrm{e}}$ & $\circ / 4 \Delta^{\mathrm{e}}$ & $\mathrm{V} \wedge^{\mathrm{a}}$ & هيدرومكس \\
\hline Q०a & $9)^{\mathrm{d}}$ & $1 / 9 y^{a}$ & $\circ / V y^{a}$ & $q^{\mu d}$ & شاهد \\
\hline $9 / \mu$ & r/VQ & $0 / Y 1$ & .09 & $r / T V$ & $\operatorname{LSD}(\circ / \circ \Delta)$ \\
\hline
\end{tabular}

حروف مشابه در هر ستون بيانكر عدم اختلاف معنىدار در سطح بنج درصد با آزمون حداقل تفاوت معنىدار (LSD) است.

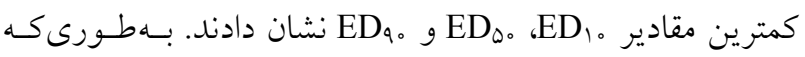
افزايش يافت (Y) (Y) (1)

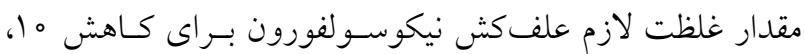
هم و •و درصد وزن خشك، تر و بقاء تاجخروس ريشـه قرمـز كارايى علف كث نيكوسولفورون

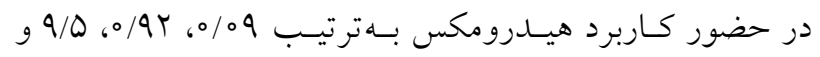
r/ هكتار بود و در غيـاب مـاده افزودنسى بـهترتيـب معـادل 4\&/ه،

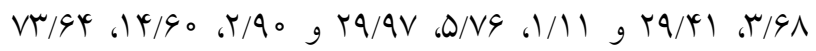
كرم ماده مؤثره در هكتار بود (جدول Vو و، ه). از سوى ديخـر نتايج نشان مىدهد كه با كاربرد مـواد افزودنسى مقـادير يتانسـيل نسـبى (R) علـف كـش نيكوسـولفورون در مقايسـه بـا كـاربرد علف كش تنها (بدون افزودنى) بهطور معنى دار افزايش مىيابـد. بهطورى كه با كاربرد مواد افزودنسى كـارايى ايسن علـف كـش در

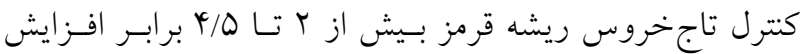
يافت و بقاء تاجخروس r تا ه برابر كاهش بيدا كرد (شـكل س). بيشترين يتانسيل نسبى علـف كـش از كـاربرد دو مـاده افزودنسى

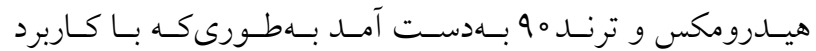
نتايج منحنى دز پاستخ وزن خشك و تر تاجخروس ريشـه قرمـز

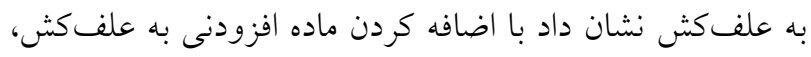

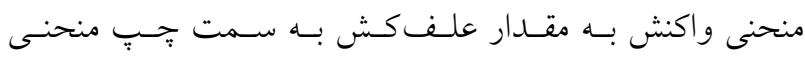

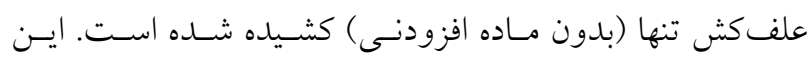

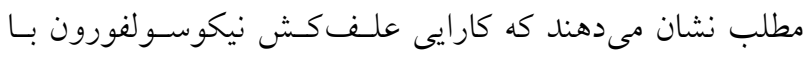

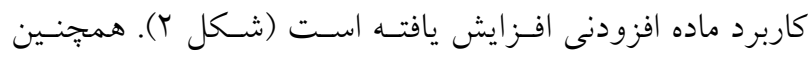

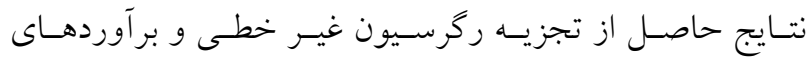
بهدست آمده از برازش مدل به وزن خشك، تر و بقاء علفهرز تاجخروس ريشه قرمز مشخص شد كه كاربرد مواد افزودنى بـا علف كش نيكوسولفوورن قادر است بِارامترهاى ـED

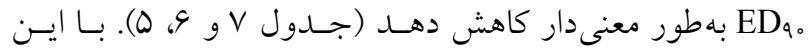
وجود، اثر مواد افزودنى در كاهش اين بارامترها يكسـان نبـود و

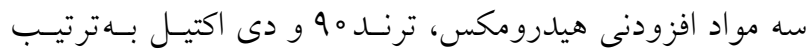



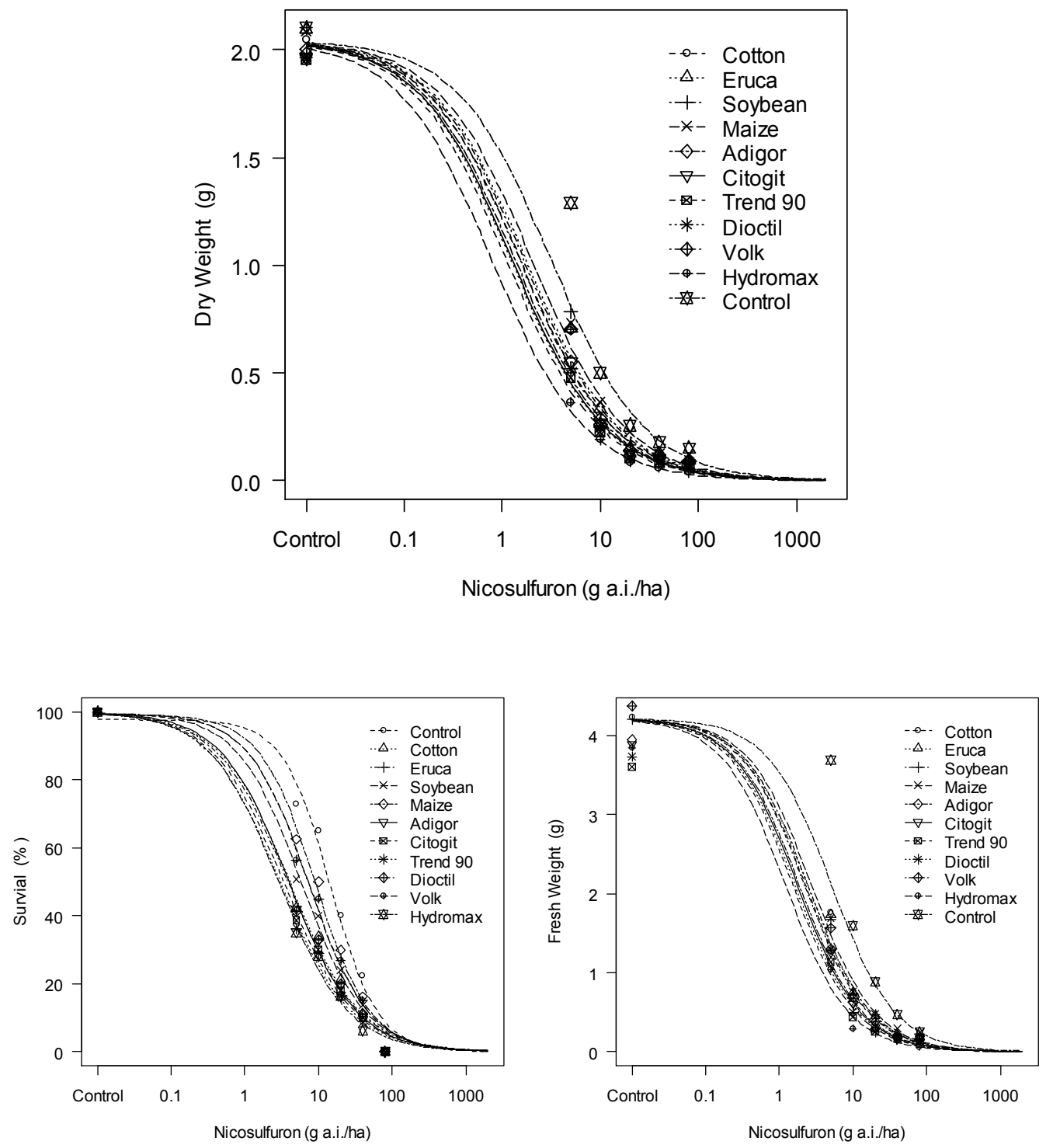

شكل Y. منحنى دز - باسخ تاجخروس ريشه قرمز به مقادير مختلف علفكث نيكوسولفورون در سطوح مواد افزودنى مختلف

علف كش مى توان مواد افزودنى را طبقهبندى نمود، بهطـورىكـه كاريى اين علف كش بر مبناى وزن خشك تـاجخهـروس ريشـهـ قرمز مىتوان بهترتيب، هيدرومكس > ترنـــه > سـيتو كيت >

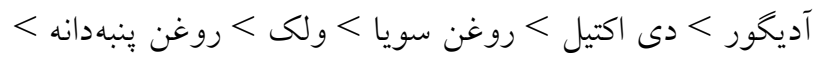
روغن منداب > روغن ذرت طبقه بندى نمود. اين نتيجهـ حساكى

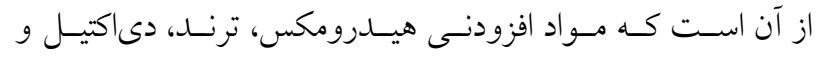
سيتو گيت بهترتيب در زمره مطلوبترين مواد افزودنى مىباشند،
اين دو ماده افزودنى كاريى علف كش نيكوسولفورون بر مبنساى

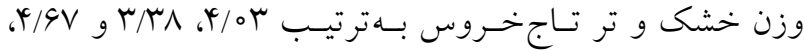

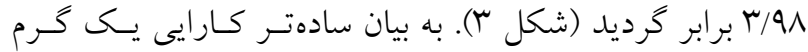
ماده مؤثره نيكوسولفورون در هكتار در حضـور هيـدرومكس و ترنده9 براى كاهش وزن خشك و تر تاجخروس معادل كارايى r

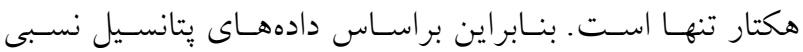


جدول ه. يارامترهاى بر آورد شده رگرسيون غير خطى براى واكنش وزن خشك تاجخروس به علف كش در سطوح مختلف مواد افزودنى

\begin{tabular}{|c|c|c|c|c|c|c|c|}
\hline RMSE & $\mathrm{R}^{r}$ & $\mathrm{ED}_{4}$ 。 & $\mathrm{ED}_{\triangleright}$ 。 & $\mathrm{ED}_{\text {।。 }}$ & شيب (b) & حد بالا (d) & تيمار \\
\hline $0 / 0 Y$ & $0 / 99$ & $|V /| F(T / M \mid)$ & $1 / 90(0 / 99)$ & $0 / 19(0 / 1 Y)$ & $0 / 94(0 / 10)$ & $T / 09(0 / T \varphi)$ & 1 \\
\hline $0 / 0 \mu k$ &.$/ 94$ & $19 / 09(4 / 19)$ & I/V०(0/VY) & $0 / 10(0 / / T)$ & $0 / 91(0 / / 4)$ & $T / 11(0 / T V)$ & r \\
\hline$\circ / \circ \wedge V$ & $\circ / \wedge V$ & $\mid N / \circ Y(Q / \circ r)$ & $1 / 4 \circ(0 / 99)$ & $0 / 11(0 / 09)$ & $0 / \wedge \varphi(0 / \mid Y)$ & $r / T r(0 / T V)$ & r \\
\hline$\circ / 09$ &.$/ 90$ & $r Y / T Y(Q / \circ Y)$ & l/Af $(0 / \mathrm{VA})$ & $0 / 10(0 / / T)$ & $\circ / \Lambda(\circ / / 0)$ & $T / T \circ(\circ / T V)$ & r \\
\hline$\circ / \circ \circ \mathrm{V}$ & $0 / 91$ & 1Q/DQ (Y/GY) & $1 / 0 \circ(0 / 91)$ & $0 / 09(0 / 01)$ & ०/^९ $(\circ / / Q)$ & $r / 01(0 / T G)$ & 0 \\
\hline $0 / 011$ & $\circ / 9 V$ & $1 \% / 90(\Gamma / 00)$ & $1 / 10(0 / 09)$ & $0 / 09(0 / 0 \wedge)$ & $0 / \wedge 9(0 / / Q)$ & $1 / 9 V(0 / 49)$ & 9 \\
\hline$\circ / \circ \circ \Delta$ & $0 / 99$ & $1 \% / \circ q(r / 00)$ & $1 / 09(0 / 09)$ & $0 / 09(0 / 01)$ & $\circ / \Lambda(0 / \mid Q)$ & I/9V $(0 / T \Delta)$ & V \\
\hline $0 / 009$ & $0 / 91$ & $1 \% / 0 \circ(\Gamma / Y q)$ & $\operatorname{ITY}(0 / 90)$ & $0 / 10(0 / 09)$ & $0 / 19(0 / 10)$ & $1 / 91(0 / 79)$ & $\wedge$ \\
\hline $0 / 0 y t$ & $0 / 9 T$ & IV/N $(\boldsymbol{Y} / \circ \Delta)$ & $1 / 40(0 / 9 \mathrm{~V})$ & $0 / 1 Y(0 / 10)$ & $0 / 19(0 / 10)$ & $T / 0(0 / T \varphi)$ & 9 \\
\hline o/o०r & $0 / 99$ & $q / 0 \circ(T / 19)$ & $0 / 9 Y(0 / 4 \wedge)$ & $0 / 09(0 / 01)$ & $0 / 94(0 / 19)$ & $1 / 99(0 / T Q)$ & 10 \\
\hline$\circ / \circ \Delta \wedge$ & $0 / 90$ & $r q / 4 \mid(D / V q)$ & $r / 9 \wedge(1 / 09)$ & $0 / \mathbb{\varphi} \varphi(0 / T Y)$ & $1 / 09(0 / 14)$ & $T / 19(0 / T V)$ & 11 \\
\hline
\end{tabular}

اعداد داخل برانتز نشاندهنده خطاى استاندارد است.

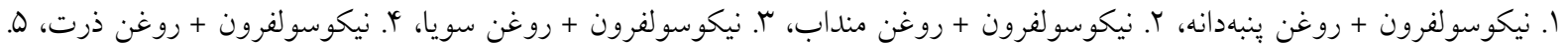

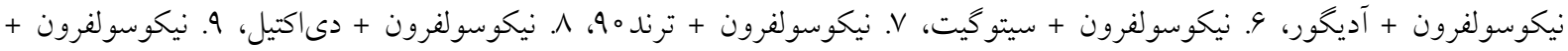

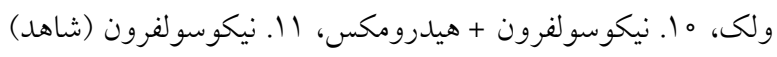

جدول و. بارامترهاى برآورد شده ركرسيون غير خطى براى واكنش وزن تر تاجخروس به علفكش در سطوح مختلف مواد افزودنى

\begin{tabular}{|c|c|c|c|c|c|c|c|}
\hline RMSE & $\mathrm{R}^{r}$ & $\mathrm{ED}_{4}$ 。 & $\mathrm{ED}_{\diamond}$ 。 & $\mathrm{ED}_{1}$ 。 & شيب (b) & حد بالا (d) & تيمار \\
\hline $0 / 091$ & $\circ / 9 V$ & $19 / 09(1 / 9 \mathrm{~V})$ & T/GY (०/AG) & $0 / T V(0 / T I)$ & $1 / 11(0 / 19)$ & T/MI (०/DV) & 1 \\
\hline $0 / Y_{0}$ & $0 / 9 T$ & $19 / 9 \wedge(Y / \mu r)$ & r/Or $(0 / \Lambda \mathrm{l})$ & $0 / Y I(0 / \mid Q)$ & $0 / 99(0 / 10)$ & $Y / D Y(0 / 90)$ & r \\
\hline 每 & $0 / 90$ & $r|/ 9|(Q / \circ V)$ & Y/OY (०/А૬ $)$ & $0 / 19(0 / 10)$ & $0 / 94(0 / 10)$ & $1 / A r(\circ / \Delta V)$ & r \\
\hline.$/ 11$ & $\circ / 90$ & $r \Psi / T(\Delta / \Delta r)$ & I/AV $(0 / \wedge r)$ & $0 / 10(0 / / \mu)$ & 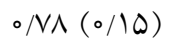 & $Y / 0 V(0 / 90)$ & 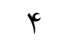 \\
\hline $0 / 0 Y$ & $0 / 91$ & $I V / 9 \circ(r / \Lambda T)$ & $1 / 94(\circ / v 9)$ & $0 / Y 1(0 / 19)$ & $0 / 10(0 / 19)$ & $\Gamma / 9 \wedge(0 / \Delta \Delta)$ & 0 \\
\hline$\circ / \circ \wedge 4$ & $0 / 90$ & $\mathrm{IV} / \circ \mathrm{V}(\mathrm{r} / 90)$ & $\operatorname{l/GY}(\circ / N Y)$ & $0 / 10(0 / / \Psi)$ & $0 / 94(0 / 19)$ & $r / q \mid(0 / D Y)$ & 4 \\
\hline $0 / 09 r$ & $0 / 99$ & $19 / 1 \Gamma(r / 90)$ & $1 / 40(\circ / N Y)$ & $0 / \mathbb{R}(0 / \mathbb{T})$ & $0 / 91(0 / 19)$ & r/GY $(0 / 01)$ & V \\
\hline $0 / 0$ pr & $0 / 9 V$ & $|q / 4|(\Gamma / \Delta \Lambda)$ & I/AK (०/NG) & $0 / T_{0}(0 / 10)$ & $1 / 0(\mathrm{IV})$ & $r / v V(\circ / \Delta r)$ & $\wedge$ \\
\hline$\circ / \circ \wedge 4$ & $0 / 99$ & $\mid \Lambda /{ }^{\prime} \omega(\Gamma / \Lambda \mid)$ & $r / 0 q(0 / V q)$ & $0 / Y Y(0 / 19)$ & $1 / 01(0 / 19)$ & $\varphi / 4 \backslash(0 / 0 q)$ & 9 \\
\hline$\circ / \circ V V$ & $0 / 99$ & $11 / V T(Y / T V)$ & $1 / 4 \pi(0 / 90)$ & $0 / 1 \pi(0 / 11)$ & $0 / 91(0 / 1 \mathrm{~V})$ & r/AG $(\circ / \Delta Y)$ & 10 \\
\hline$\circ / 0 \Lambda$ & $\circ / \wedge \Delta$ & rq/৭V (Y/AV) & $\Delta / V \varphi(1 / T \varphi)$ & $1 / 11(0 / \mathbb{K} Y)$ & 1/19) & $0 / 0 V(0 / 91)$ & 11 \\
\hline
\end{tabular}

اعداد داخل يرانتز نشاندهنده خطاى استاندارد است.

ا. نيكوسولفرون + روغن ينبهدانه، r. نيكوسولفرون + روغن منداب، r. نيكوسولفرون + روغن سويا، أ. نيكوسولفرون + روغن ذرت،

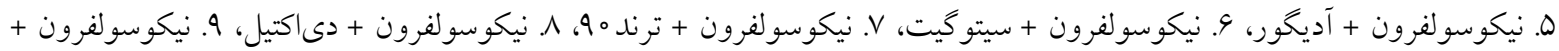

ولك، ما. نيكوسو لفرون + هيدرومكس، 11. نيكوسولفرون (شاهد) 


\begin{tabular}{|c|c|c|c|c|c|c|c|}
\hline RMSE & $\mathrm{R}^{r}$ & $\mathrm{ED}_{4}$ 。 & $\mathrm{ED}_{\emptyset}$ 。 & $\mathrm{ED}_{\text {।。 }}$ & شيب (b) & حد بالا (d) & تيمار \\
\hline VA & ./9r & $\varphi Q / \Delta r(19 / \Delta r)$ & $r / \circ q(1 / T r)$ & $\circ / T V(0 / T V)$ & $0 / 91(0 / 19)$ & $৭ ৭ / \vee \wedge(0 / 94)$ & 1 \\
\hline 90 &.$/ 9 T$ & $\Delta V / \circ \circ(19 / 94)$ & V/Tr (I/RV) & $0 / 94(0 / 4 y)$ & $1 / \circ V(\circ / \backslash \Lambda)$ & $99 / 44(0 / 94)$ & r \\
\hline$|\mu|$ & $0 / 9 \circ$ & $\Delta Y / \circ r(19 / V \Lambda)$ & Q/^G (1/Tr) & $0 / 99(0 / 49)$ & $1 / \circ V(1 / \pi \Psi)$ & $99 / 90(0 / 90)$ & r \\
\hline Ifr & $\circ / 19$ & $01 / 91(19 / 19)$ & $q / \circ V(1 / 0 r)$ & $1 / T V(0 / 09)$ & $1 / 19(0 / 11)$ & $99 / \Gamma 1(0 / 91)$ & $r$ \\
\hline 114 & $0 / 91$ & $r \circ / F r(|K / T|)$ & $\mathrm{r} / 9 \mathrm{~V}(1 / \circ \mathrm{V})$ & $0 / T_{q}\left(0 / T_{\Lambda}\right)$ & $0 / 90\left(0 / r_{0}\right)$ & $99 / \wedge 1(0 / 94)$ & 0 \\
\hline 19 & . & rN/OY $(\mid Y / T G)$ & $\Gamma / \mu \Delta(1 / 04)$ & $\circ / \Gamma \circ(\circ / T \Delta)$ & $1 / 0 \circ(\circ / \backslash \wedge)$ & $99 / 94(9 / 4 \mathrm{~V})$ & 4 \\
\hline $9 \mathrm{~V}$ & $0 / 9 Y$ & $\mu \Psi / D \mid(\mid r / 0)$ & $r / \circ r(1 / 0 Y)$ & $0 / K G(0 / Y Y)$ & $0 / 9 \circ(0 / T Y)$ & $৭ 9 / \wedge \wedge(\Delta / 9 \mu)$ & V \\
\hline TGA & $\circ / \Lambda 1$ & $4+/ 99(19 / 1 T)$ & r/Aץ (1//०) & $0 / M Y(0 / Y Y)$ & $0 / 9 \circ\left(0 / T_{0}\right)$ & $99 / \Lambda)(0 / 94)$ & $\wedge$ \\
\hline $19 \pi$ & $\circ / \wedge \Delta$ & $\Delta V / \circ \circ(19 / 9 \pi)$ & V/Tr (1/R4) & $0 / 94(0 / 4 y)$ & $1 / \circ \vee(\circ / \backslash \Lambda)$ & $99 / 40(0 / 94)$ & 9 \\
\hline gr &.$/ 90$ & TI/TG $(11 / 01)$ & $r / 9 \circ(1 / 01)$ & $\circ / T V(0 / Y Y)$ & $0 / 9 T(0 / T r)$ & $৭ ৭ / \wedge \vee(D / 9 \Psi)$ & 10 \\
\hline 110 & $0 / 91$ & $V r / G Y(I V / I I)$ & $14 / 9 \circ(Y / T q)$ & $r / 9 \circ(1 / \circ \Delta)$ & $1 / K_{Y}\left(0 / T_{Y}\right)$ & $৭ \vee / ৭ Q(\Delta / V Y)$ & 11 \\
\hline
\end{tabular}

اعداد داخل خيرانتز نشاندهنده خطاى استاندارد است.

ا. نيكوسولفرون + روغن ينبهدانه، r. نيكوسولفرون + روغن منداب، گr. نيكوسولفرون + روغن سويا، ؟. نيكوسولفرون + روغن ذرت، ه. نيكوسولفرون + آديخور، 9. نيكوسولفرون + سيتو گيت، V. نيكوسولفرون + ترند 9.، م. نيكوسولفرون + دىاكتيل، 9.

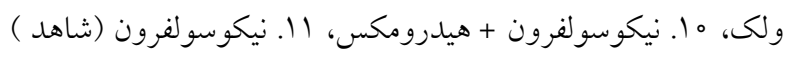

كلودينافوبٍ يرويارزيل مى توان كارايى كنترل يولاف وحشسى را

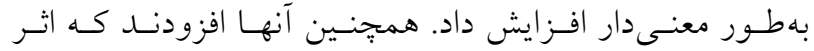

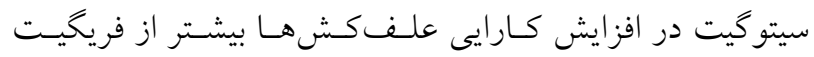
مىباشد. در آزمايشى مشخص شد با افزودن سـولفات آمونيـوم يا ماده ايكسجهـنج (X-change) مسى تـوان كـارايى علـف كـش كليفوسيت در كنترل خارشتر افـزايش داد (Y). كـارايى اخـتلاط علـــكـش كليفوسـيت و توفــوردى در كنتـرل شـيرينبيـان مسى (Glylycyrrhiza glabra L.)

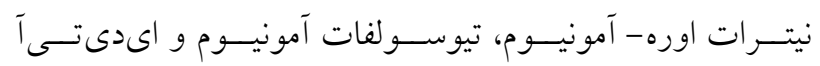

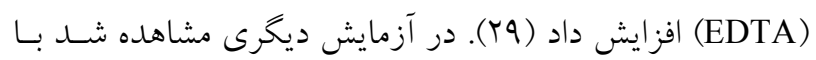
كاربرد ماده افزودنى فرگيت، كارايى علف كش كوئين كلـراك در كنترل علـف هــاى هـرز شـيرتيغك (Sonchus oleraceus L. و و

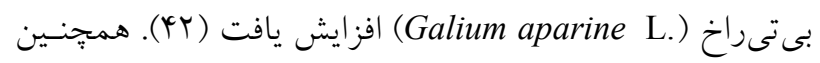
كارايى علف كـش نيكوسـولفورون در كتــرل علـف هــاى هـرز سوروف (Echinochloa crus- galli (L.) P.Beauv.) و گاوينبـه نيز با كاربرد مواد افزودنى (Abutilon theophrasti Mediucus.)
در مقابل روغن ذرت و ولكى با كمترين اثر ضعيفترين كـارايى از خود بروز دادند (شكل س).

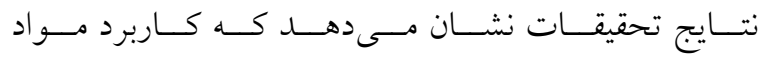

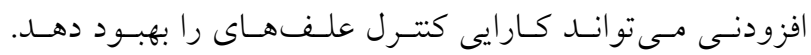

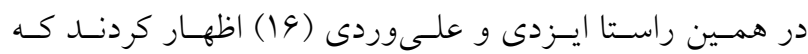
كـاربرد مــواد افزودنـى كرجهـك، زيتـون، كـانولا، ســويا، ينبــه، كنجــ، بــرزك (Linum usitatissimum L.)، كلـزا، بــادامزمينسى (Arachis hypogaea L.)

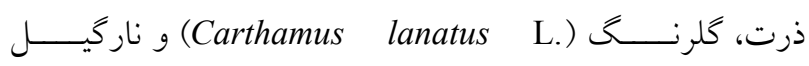
بــــا دو علــــــ (Cocos nucifera L.) (سولفوســولفورون) و توتــال (سولفوســولفورون + متســولفورون متيل) قادرند كارايى كترل جـودره (Hordeum spontaneum Koch)

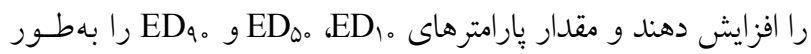
معنى دار كاهش دهند. براساس نتايج جيتبند و همكاران (N) با كاربرد مواد افزودنى سيتو گيت و فريخيت در اختلاط يـا كـاربرد

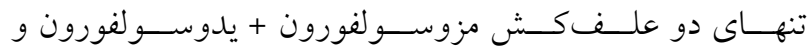



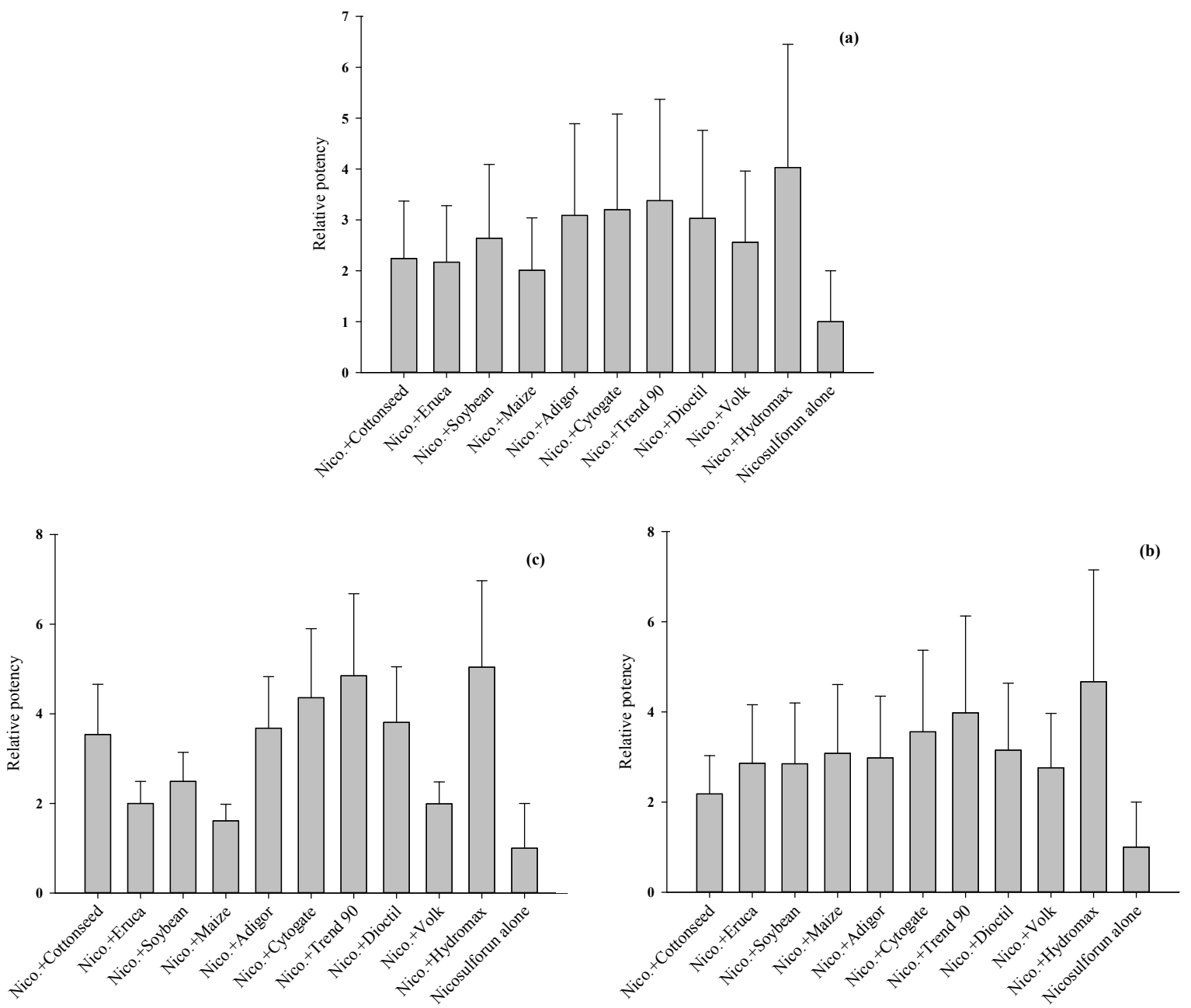

شكل r. نمودار بتانسيل نسبى علف كش بر مبناى وزن خشك (a)، وزن تر (b) و بقا (c) تاجخروس ريشه قرمز در سطوح مواد افزودنى، خطوط بر روى هر ستون نشاندهنده خطاى استاندارد است.

افزودنى اتتيلوس (Atplus 60 EC)، آديـروس (Adpros 85 SL)

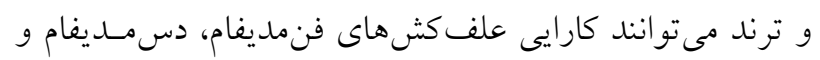

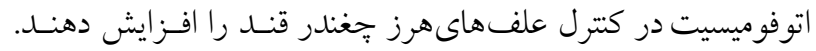

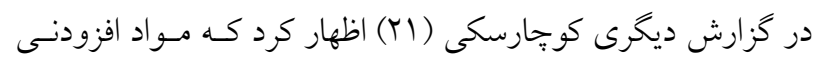

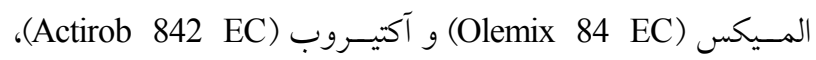

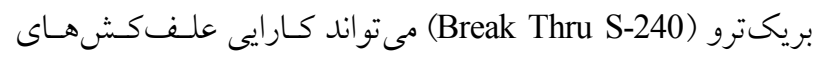
فنمديفام، دسمديفام و اتوفوميسـيت را افززايش دهنـــ. مطالعـات

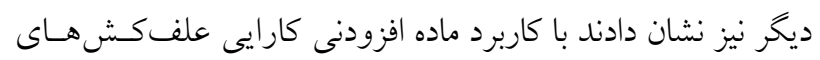

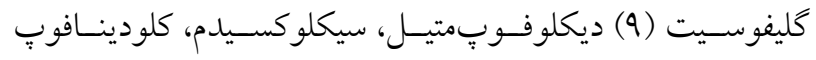
يرويارزيل (YY)، ايماز امتابنز متيل و سولفوسـولفورون (V و ا IY).

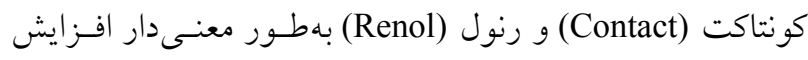

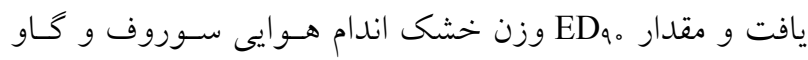

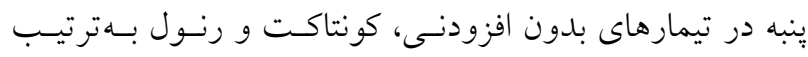
ه/ D/N

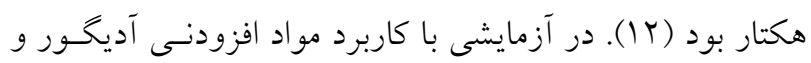

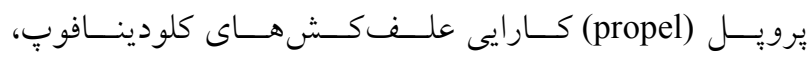
هالو كسى فوبِيى متيل و دايفنزوكـوات متيـلسـولفات در كتتـرل

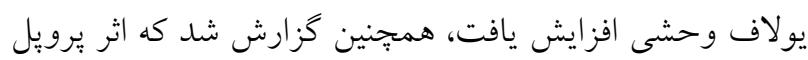

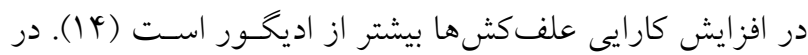
مطالعات كوجاراسكى و سادوويسكى (Yr) اذعان شده كه مـواد 


$$
\text { افز ايش ميى نابد. }
$$

\section{منابع مورد استفاده}

1. Aliverdi, A., M. H. Rashed-Mohassel, E. Zand and M. Nassiri-Mahallati. 2009. Increased foliar activity of clodinafop propargyl and tribenuronmethyl by surfactants and their synergistic action on wild oat (Avena ludoviciana) and wild mustard (Sinapis arvensis). Weed Biology and Management 9: 292-299.

2. Babaei, S., H. Alizadeh, M. A. Baghestani and M. R. Naqhavi. 2014. Effect of some adjuvants on sulfosulfuron efficacy in hordeum spontaneum control in wheat fields. Iranian Journal of Weed Science 10: 121-132. (In Farsi)

3. Baghestani, M. A., E. Zand, F. Lotfi-Mavi, H. Esfadiari, R. Pourazar and E. Mamnoie. 2013. Evaluation of spectrum efficacy of registered herbicides used in corn. Journal of Plant Pests and Diseases 81: 100-122. (In Farsi).

4. Bazoobandi, M., M. Abbas poor, H. Torabi and P. Keshavarz. 2013. Effects of additive to ease hard water impacts as a carrier on glyphosate (Roundup SL 41\%) efficiency and its effect on some growth parameters of camelthorn (Alhagi psedoalhagi). Iranian Journal of Weed Science 175-185. (In Farsi)

5. Bunting, J. A., C. L. Sprague and D. E. Riechers. 2004. Proper adjuvant selection for foramsulfuron activity. Crop Protection 23: 361-366.

6. Bunting, J., C. L. Spar age and D. E. Riechers. 2005. Incorporating Foramsulfuron into annual weed control systems for corn. Weed Technology 19: 160- 167.

7. Cabanne, F., J. Gaudry and J. C. Streibig. 1999. Influence of alkyl oleates on efficacy of phenmedipham applied as an acetone: water solution on Galium aparine. Weed Research 39: 57-67.

8. Chitband, A. A., R. Ghorbani, M. H. Rashed Mohassel, A. Zare Faizabadi and M. Abbaspoor. 2013. Isobolographic analysis for additive, synergism and antagonism in binary mixture of mesosulfuron + iodosulfuron and clodinafoppropargyl and optimizing them with citowett and frigate surfactants on wild oat (Avena ludoviciana). Iranian Journal of Weed Science 9: 93-104. (In Farsi)

9. Gauvrit, C., T. Muller, A. Milius and G. Trouve. 2007. Ethoxylated rapeseed oil derivatives as non-ionic adjuvants for glyphosate. Pest Management Science 63: 707-713.

10. Ghorbani, A. A., E. Zand, M. A. Baghestani, S. Forozesh, M. Abdollahian Noghabi and M. Kazemi Poresfahlan. 2007. Study on different concentrations of adjuvant and chloridazon + phenmedipham on yield and yield components of sugar beet (Beta vulgaris L.). Environmental Science 5(1): 37-52. (In Farsi)

11. Green, J. M. and G. B. Beestman. 2007. Recently patented and commercialized formulation and adjuvant technology. Crop Protection 26: 320-327.

12. Hajmohammadnia-Ghalibaf, K., S. Mathiassen, P. Kudsk and S. A. Hosseini. 2013. Effective of adjuvants on nicosulfuron performance in presence of ions in the spray solution. In: Proceeding of the $5^{\text {th }}$ Iranian Weed Science Congress, Karaj, Iran. pp: 608-611. (In Farsi)

13. Hall, F. R., A. C. Chapple, R. A. Downer, L. M. Kirchner and J. R. M. Thacker. 1993. Pesticide application as affected by spray modifiers. Pesticide Science 38:123-133.

14. Hammami, H., A. Aliverdi and M. Parsa. 2014. Effectiveness of clodinafop-propargyl, haloxyfop-p-methyl and difenzoquat-methyl-sulfate plus Adigor ${ }^{\circledR}$ and Propel ${ }^{\mathrm{TM}}$ adjuvants in controlling Avena ludoviciana Durieu. Journal of Agricultural Science and Technology 6: 291-299.

15. Hammami, H., M. H. Rashed-Mohassel, M. Parsa, M. Bannayan Avala and E. Zand. 2013. Optimizing dosage of sethoxydim with vegetable oils to control wild oat (Avena ludoviciana Durieu.). Advanced Crop Science 3: 687- 
694.

16. Izadi-Darbandi, E. and A. Aliverdi. 2015. Optimizing sulfosulfuron and sulfosulfuron plus Metsulfuronmethyl activity when tank-mixed with vegetable oil to control wild barley (Hordeum spontaneum Koch.). Journal Agriculture Science Technology 17: 1769-1780.

17. Izadi-Darbandi, E., A. Aliverdi and H. Hammami. 2013. Behavior of vegetable oils in relation to their influence on herbicides' effectiveness. Industrial Crops and Products 44: 712-717.

18. Izadi-Darbandi, E., M. H. Rashed-Mohassel, G. Mahmoudin and M. Dehghan. 2013. Evaluation of some crops tolerance to Granstar (Tribenuron methyl) herbicide soil residual. Journal of Plant Protection 26: 362-369. (In Farsi).

19. Knezevic, S. Z., S. F. Weise and C. J. Swanton. 1994a. Interference of redroot pigweed (Amaranthus retroflexus L.) in corn (Zea mays L.) Weed Science 42: 568-573.

20. Knezevic, Z. S., M. Horak and R. Vanderlip. 1994b. Relative time of redroot pigweed (Amaranthus retroflexus L.) emergence is critical in pigweed-sorghum [Sorghum bicolor (L.) Moench] competition. Weed Science 42: 502508.

21. Kucharski, M. 2007. Impact of adjuvants on: phenmedipham, desmedipham and ethofumesate residues in soil and plant. Pestycydy 3-4: 53-59.

22. Kucharski, M. and J. Sadowskim. 2006. Effect of adjuvants on herbicide residues level in soil and plant. Journal of Plant Diseases and Protection 20: 971-975.

23. Kudsk, P. 2008. Optimizing herbicide dose, a straight forward approach to reduce the risk of side effects of herbicides. Environmentalist 28: 49-55.

24. Mamnoie, E. and M. A. Baghestani, 2013. Investigating possibility of tank mixture of nicosulfuron + rimsulfuron (Ultima) with bromoxynil + MCPA (Bromicid MA) for weed control in corn in Jiroft. Journal of Plant Protection 27: 37-47.

25. Mamnoie, E. and M. A. Baghestsni. 2014. Investigating efficacy of the tank mixture of nicosulfuron (Cruz) plus bromoxynil + MCPA (Bromicide MA) for weed control in corn in Jiroft. Journal of Plant Protection 28: 211-219.

26. Mirshekari, B., A. Dabbagh mohammadi nasab, A. Javanshir, G. Noormohammadi and H. Rahimian mashhadi. 2007. Effects of redroot pigweed (Amaranthus retroflexus L.) competition on yield and yield components of sunflower hybrid Azarghol (Helianthus annuus L.). Journal of Agricultural Science Islamic Azad University 13(1): 171-179. (In Farsi).

27. Mousavinik, A., E. Zand, M. A. Baghestani, R. Deihimfard, S. Soufizadeh, F. Ghezeli and A. Aliverdi. 2009. Ability of adjuvants in enhancing the performance of pinoxaden and clodinafop propargyl herbicides against grass weeds. Iranian Journal of Weed Science 5: 65-77.

28. Nielsen, O. K., C. H. Ritz and J. C. Streibig. 2004. Nonlinear mixed model regression to analyze herbicide doseresponse relationships. Weed Technology 18: 30-37.

29. Nosratti, I., H. Alizade and H. Rahimian Mashhadi. 2011. Effect of some adjuvants on overcoming antagonistic effects of spray carrier water quality on glyphosate and herbicide mixture 2,4-D+MCPA efficacy on Licorice (Glycyrrhiza glabra). Journal of Plant Protection 7: 49-60. (In Farsi).

30. Pimentel, D. 1995. Amounts of pesticides reaching the target pests: environmental impacts and ethics. Journal of Agricultural and Environmental Ethics 8: 17-29.

31. Poppell, C. A., R. M. Hayes, T. C. Mueller. 2002. Dissipation of nicosulfuron and rimsulfuron in surface soil. Journal of Agricultural and Food Chemistry 50: 4581-4585

32. Rajcan, I. and C. J. Swanton. 2001. Understanding maize-weed competition: resource competition, light quality and the whole plant. Field Crops Research 71: 139-150.

33. Ramsey, R. J. L., G. L. Stephenson and J. C. Hall. 2006. Effect of humectants on the uptake and efficacy of glufosinate in wild oat (Avena fatua) plants and isolated cuticles under dry conditions. Weed Science 54: $205-211$.

34. Rashed Mohassel, M. H., A. Aliverdi, H. Hammami and E. Zand. 2010. Optimizing the performance of diclofopmethyl, cycloxydim, and clodinafop-propargyl on little seed canary grass (Phalaris minor) and wild oat (Avena ludoviciana) control with adjuvants. Weed Biology and Management 10: 57-63.

35. Sarabi, V., A. Ghanbaria, M. H. Rashed Mohassela, M. Nassiri Mahallatia and M. Rastgooa. 2014. Evaluation of broadleaf weeds control with some post-emergence herbicides in maize (Zea mays L.) in Iran. International Journal of Plant Production 8(1): 19-32.

36. Shahbazi, S., H. Alizadeh and K. Talebi Jahromim. 2015. Study of nicosulfuron + rimsulfuron (ultima) residues in maize filed by bioassay. Iranian Journal of Field Crop Science 1: 15-24. (In Farsi)

37. Sharma, S. D. and M. Singh. 2000. Optimizing foliar activity of glyphosate on Bidens frondosa and Panicum maximum with different adjuvant types. Weed Research 40: 523- 533.

38. Sharma, S. D., R. C. Kirkwood and T. I. Whateley. 1996. Effect of non-ionic nonylphenol surfactants on surface physicochemical properties, uptake and distribution of asulam and diflufenican. Weed Research 36: $227-239$. 
39. Si, Y., J. Zhou Chen, H. D. Zhou and Y. Yue. 2004. Effects of humic substances on photodegradation of bensulfuron-methyl on dry soil surfaces. Chemosphere 56: 967-972.

40. Thelen, K. D., E. P. Jackson and D. Penner. 1995. Utility of nuclear magnetic resonance for determining the molecular influence of citric acid and an organosilicone adjuvant on glyphosate activity. Weed Science 43: 566571.

41. Young, B. G. and S. E. Hart. 1998. Optimizing foliar activity of isoxaflutole on giant foxtail with various adjuvants. Weed Science 46: 397-402.

42. Zawierucha, J. E. and D. Penner. 2001. Adjuvant Efficacy with Quinclorac in Canola (Brassica napus) and Turf Grass. Weed Technology 15: 220-223. 


\title{
Investigating the Effect of Adjuvants on Nicosulfuron Efficacy in Controlling Redroot Pigweed (Amaranthus retroflexus)
}

\author{
E. Mamnoie ${ }^{1}$, E. Izadi Darbandi2 ${ }^{\star}$, M. Rastgoo², M. A. Baghestani ${ }^{3}$ and M. Hasanzade ${ }^{4}$
}

(Received: June 15-2016; Accepted: August 30-2017)

\begin{abstract}
In order to study the efficacy of nicosulfuron in the control of redroot pigweed (Amaranthus retroflexus L.) using adjuvants, a greenhouse experiment was conducted at the Research Greenhouse, Faculty of Agriculture, University of Ferdowsi, Mashhad, Iran. The experiment was carried out as a factorial based on a randomized complete block design with four replications. Treatments included adjuvant application in 11 levels (cotton oil, rapeseed oil, soybean oil, maize oils, Adigor ${ }^{\circledR}, \operatorname{Volck}{ }^{\circledR}$, HydroMax ${ }^{\mathrm{TM}}$, Cytogate, Trend ${ }^{\circledR}$ 90, D-octil ${ }^{\circledR}$ and control (without the adjuvants), doses of nicosulfuron in six levels: 0 (control), 5, 10, 20, 40, and $80 \mathrm{~g}_{\text {a.i ha }}^{-1}(0,6.25,1205,25,50$, and $100 \%$ recommended herbicide dose). Dry weight, fresh weight, survival and control percent were measured. The results showed that herbicide rate, adjuvant use and their interaction had a significant effect on the examined attributes. Dry weight, fresh weight and pigweed survival were decreased, while the control percent was increased significantly, when herbicide dose was enhanced. Also, the results showed that by using the adjuvants, ED10 ED50 and ED90 values were decreased significantly, while nicosulfuron efficacy in the redroot pigweed control was raised significantly; further, the highest relative potential of hebricide was obtained by $\operatorname{HydroMax}^{\mathrm{TM}}$ and Trend ${ }^{\circledR}$. In other words, when HydroMax ${ }^{\mathrm{TM}}$ and

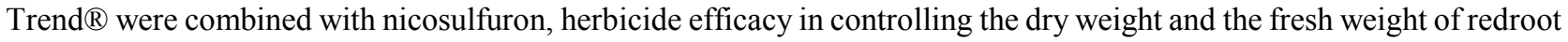
pigweed indicated a three-fold increase.
\end{abstract}

Keywords: ED50, HydroMax ${ }^{\mathrm{TM}}$, Trend® 90

1. PhD Graduate of Weed Science of Ferdowsi University of Mashhad and Plant Protection Research Department, South Kerman Agricultural and Natural Resources Research and Education Center, AREEO, Jiroft, Iran.

2. Associate Professor, Faculty of Agriculture Ferdowsi University of Mashhad, Mashhad, Iran.

3. Researcher Professors, Iranian Plant Protection Research Institute, Tehran, Iran.

4. Professors, Faculty of Pharmacy, Mashhad University of Medical Sciences, Mashhad, Iran.

*. Corresponding Author, Email: e-izadi@um.ac.ir 